\title{
Clostridium difficile infection of the gut
}

\author{
A P Dodson, S P Borriello
}

\section{Introduction}

Many species of clostridia are capable of causing disease of the gut, ${ }^{1}$ the most common of which in hospitals is that due to Clostridium difficile. $C$ difficile is now recognised as the cause of pseudomembranous colitis (PMC) and many cases of antibiotic associated diarrhoea, although some cases of extraintestinal $C$ difficile infection have also been reported. ${ }^{2}$ This pathogen is presently of major concern in many hospitals $^{3}$ where it is a frequent cause of infection, particularly in the elderly.

PMC was first described as a postoperative complication at the end of the 19th Century ${ }^{4}$ and is now well defined histopathologically. ${ }^{5}$ However, the causative agent was not known, and it was not until the mid-1970s that its association with antimicrobial therapy was identified.

In the 1940s it was initially thought that PMC was a result of postoperative shock, until the introduction and widespread use of broad spectrum antimicrobial agents, including streptomycin, penicillin and chloramphenicol, indicated a connection between antibiotic use and isolation of antibiotic resistant staphylococci. Staphylococcus aureus was implicated as the causative agent. ${ }^{6}$ This, however, was not the consensus of opinion. Dawson-Edwards and Morrissey ${ }^{7}$ could only find evidence of $S$ aureus in one of 35 cases of enterocolitis following gastrointestinal surgery. Furthermore, the association with the use of clindamycin, a highly active antistaphylococcal agent, and cases of PMC was striking. ${ }^{8}$ These observations stimulated an intense period of research.

In work carried out in the USA, it was shown that hamsters treated with antibiotics could be cross-infected by intracaecal injection of the caecal contents from diseased animals. ${ }^{10}$ Furthermore, the cytopathic effect of caecal filtrates from diseased animals could be neutralised by $C$ sordellii antitoxin. ${ }^{11}$ This gave rise to the assumption that it was this organism that was responsible for the disease. However, it was not found to be present in the caecal contents of the diseased animals, whereas $C$ difficile was. It was soon shown that $C$ difficile produces cytopathic toxins that are neutralised e-mail:

paul.dodson@nottingham.ac.uk

Accepted for publication 7 March 1996 by $C$ sordellii antitoxin. ${ }^{12}$ It is now known that $C$ sordellii produces two toxins, haemorrhagic toxin (HT) and lethal toxin (LT) which are very similar to $C$ difficile toxins $\mathrm{A}$ and $\mathrm{B}$, respectively. ${ }^{13}$ In both cases the $\mathrm{N}$-termini of the toxins have a high degree of similarity and each pair of toxins is immunogenically related.

The identification of $C$ difficile as the aetiological agent of PMC in humans soon followed the identification of its casual role in experimental animal disease. ${ }^{121415}$

\section{Pathology and pathogenesis}

$C$ difficile infection can range from mild diarrhoea to PMC. The symptoms of the disease typically develop after approximately five to 10 days, although this can be delayed for up to two to 10 weeks after discontinuation of antimicrobial therapy. ${ }^{16}$ The commonest symptom is a sudden onset of mild diarrhoea, which is foul smelling and contains mucus. Patients with antibiotic associated colitis have profuse diarrhoea, abdominal pain and distension, accompanied by nausea, fever and dehydration.

Gastrointestinal examination of patients with PMC reveals a characteristic picture. At the onset of the disease, 1-2 $\mathrm{mm}$ white/yellow plaques appear on the mucosa, which increase in size and coalesce to form larger plaques as the disease progresses. A closer examination reveals typical mushroom-like pseudomembranes erupting from the colonic mucosa, which are comprised of fibrin, mucus, leucocytes, and cellular debris. However, this inflammation is not necessarily confluent in the mucosa and even a single biopsy specimen may show patchy inflammation. ${ }^{17}$

It is accepted that the association between $C$ difficile infection and antibiotic therapy is dependant on the disruption of the normal gut microbiota by antimicrobials before the organism can establish and cause disease. This barrier effect to infection afforded by the normal microbiota is commonly referred to as colonisation resistance. It is often the nature of the antibiotic that is important in determining whether a patient will develop a $C$ difficile infection, the cephalosporins and penicillins being particularly implicated..$^{19}$ In a recent study in Wales, in which 31 of 232 hospital admissions studied tested positive for $C$ difficile toxin $\mathrm{A}$, the antibiotics most commonly 
associated with these positive cases were those that exhibited a broader spectrum of activity. ${ }^{20}$

Not everyone seems to be equally susceptible to $C$ difficile infection, the elderly being at the greatest risk. ${ }^{21}$ It is possible that this higher incidence of infection is due to their poorer colonisation resistance to infection. ${ }^{22}$ It remains unclear as yet why neonates, who are in the process of producing a complex gut bacterial ecosystem, remain unaffected, even though $C$ difficile and its toxins are frequently present in their faeces. ${ }^{2324}$

There are many factors produced by the organism which are thought to contribute to its pathogenicity, including toxin production, protease secretion, presence of fimbriae, and capsule production. ${ }^{25}{ }^{26}$ The most important and widely studied of these is toxin production.

\section{Role and molecular aspects of $C$ difficile toxins}

Toxigenic strains of $C$ difficile produce two large protein toxins, toxin $\mathrm{A}$ and toxin $\mathrm{B}$, commonly (though erroneously) referred to as the enterotoxin and cytotoxin, respectively, both of which have been cloned and sequenced. ${ }^{27} 28$ Both are cytotoxic to cells in tissue culture, although toxin $\mathrm{B}$ is considerably more cytotoxic than toxin A for most cell lines. Unlike toxin $\mathrm{B}$, toxin $\mathrm{A}$ also has the ability to haemagglutinate human red blood cells. Although the toxins share $64 \%$ sequence homology, many authors consider that it is toxin $\mathrm{A}$ that is active in the intestinal tract and hence responsible for the pathology. However, recent work with human colonic mucosa indicates that toxin $B$ may be approximately 10 -fold more active on a molar basis than toxin $\mathrm{A}$ in causing damage in humans. ${ }^{29}$ Unfortunately, before absolute conclusions can be drawn, it would have to be shown that tissue from animals that fails to show damage in response to toxin $\mathrm{B}$ alone, remains insensitive to this in the in vitro Ussing chamber model. Nevertheless, the findings are both important and exciting. Studies have shown that toxin $B$, in the absence of toxin $A$, has no effect on the gut of experimental animals.

The carboxyl terminal of toxin A consists of 38 repeat units which contain epitopes for the monoclonal antibody PCG-4, used in most diagnostic kits, and includes the binding region for a Gal $\alpha 1-3 \mathrm{Gal} \beta 1-4 \mathrm{GlcNAc}$ carbohydrate receptor, which may be involved in binding of the toxin to cells in the gut. ${ }^{28}$ It has been suggested that toxin $\mathrm{A}$ initiates cell damage which allows toxin $B$ access to the cells beneath the mucosa where it can exhibit its cytopathic effect, resulting in disruption of the cell cytoskeleton. ${ }^{30}$ The mechanism of action of these toxins is not yet fully understood. It has recently been shown that they both act on the low molecular mass GTP binding proteins, Rho, known to be involved in regulation of the microfilament cytoskeleton. ${ }^{31}$ Giry et $a l^{33}$ have shown that RhoA, RhoB and RhoC are substrates for both toxins, resulting in the disruption of $\mathrm{F}$-actin structures within the cell.
Furthermore, toxin $\mathrm{B}$ has been shown to glucosylate RhoA specifically, affecting its function. ${ }^{34}$

Both toxin genes are chromosomal and are located on a 19.6 kilobase toxigenic element, which is comprised of five open reading frames $\Omega$ (ORFs), three small ORFs and the toxin A andF $B$ genes. ${ }^{35}$ The function, if any, of the three small ORFs is unknown. This region has recently been shown to be common only to $\%$ toxigenic strains. In non-toxigenic strains this $\overrightarrow{\overline{\mathrm{F}}}$ 19.6 kilobase region of the genome is $\operatorname{com}=\overrightarrow{7}$ pletely absent and in its stead there is a stretch of 127 base pairs of non-coding DNA, although the flanking regions in this part of the genomic DNA are identical in both toxigenico and non-toxigenic species. ${ }^{35}$ This is indicative of a transpositional event in the acquisition or. deletion of the toxin genes.

As yet, no strain has been found that contains only one of the toxin genes, althougho there is a report that a toxin $\mathrm{B}$ positive/toxin $\mathrm{A}$ : negative strain had been isolated, which was. - virulent in a hamster model. ${ }^{36}$ The toxin $\mathrm{B}$ of this strain seemed to be more toxic than that produced by the classically well defined strain ${ }^{3}$ VPI 10643. It later emerged that this strain $\operatorname{did}_{c}$ in fact have the first 2 kilobases of the toxin $\mathrm{A}$ $\mathrm{N}$-terminus. ${ }^{37}$ However, what effect this had on $-\overrightarrow{0}$ the pathogenicity of the organism is unknown.\&

Some variation in the size and DNA. sequence of the toxin $\mathrm{B}$ gene has been foundo between certain toxigenic $C$ difficile strains. ${ }^{37} 38 \leq$ A correlation between these changes and the cytopathicity of these different toxins has been drawn and has given some insight as to which areas of the toxin may be responsible for theo cytopathic effect seen. Eichel-Streiber et al,$^{38}$ in comparing toxin B produced by two toxigenic strains, which have distinctly different levels of cytotoxicity, have shown that the majority of the changes in the amino acid composition of the two toxins are clustered within the $\mathrm{N}$-terminal third of the proteins, and concluded that it is this domain that carries the toxic determinants.

\section{Diagnosis and treatment}

Isolation of $C$ difficile from faecal samples, $N$ although important, is not in itself a conclusive diagnostic test for disease, ${ }^{39}$ as it is possible too harbour the organism asymptomatically. There are commercially available enzyme linked ${ }_{\overparen{\varnothing}}^{\complement}$ immunoassay kits ${ }^{40}$ that rely on the detection of $\stackrel{5}{+}$ toxin A in faecal samples, based on the PGC-4 monoclonal antibody reaction with part of the repeat sequence of the toxin A molecule. These $\stackrel{\Phi}{\mathscr{}}$ kits provide a rapid and reliable method of diagnosis and further confirmation may be obtained by application of faecal filtrates too cells in tissue culture and monitoring cyto-0 pathic effects.

Treatment of the infection can often be achieved by cessation of the offending antibiotic. Although diarrhoea may cease within 48 hours, care must be taken to ensure replenishment of lost fluids. In cases where specific treatment is indicated vancomycin or metronidazole are the drugs of choice. ${ }^{41}$ 
Relapses of $C$ difficile colitis are not uncommon and can be more difficult to treat. The use of Saccharomyces boulardii as a biotherapeutic agent in conjunction with oral vancomycin has been shown to reduce the failure rate of treatment. ${ }^{42}$ Recently, a report has shown that treatment with brewer's yeast ( $S$ cerevisiae) alone has enabled four patients, who had suffered relapses even after extensive treatment with vancomycin, to recover completely from a $C$ difficile infection. ${ }^{43}$ However, this was an uncontrolled study and further work is necessary to assess the viability of such a therapy, which, if successful, could provide an inexpensive alternative to antibiotic treatment.

\section{Epidemiology and control}

It is still unclear whether existing $C$ difficile in the gut or exposure to an external source at the time of susceptibility is responsible for infection, although the weight of evidence is in favour of infection in the vast majority of cases. Hamster models have shown that clindamycin treated animals did not develop $C$ difficile infection if held in a protective environment, and further showed that $C$ difficile may be transmitted from one animal to another. ${ }^{15}$

In a clinical environment spread of the organism is thought to be the result of ingestion of spores. These are stable in the environment for several months and contamination of floors, toilets, bedpans, and furniture can arise, especially in areas where patients with $C$ difficile infection have been treated. ${ }^{44}$ Patients with existing $C$ difficile infections are thought to be the main source of infection for other patients and although asymptomatic excretion may play some part, there is no conclusive evidence as yet. Reported carriage rates in healthy adults have varied from $0-3 \%$ in Europe and up to $15 \%$ in Japan, although these differences may only be due to variations in subject selection and methods of isolation of the organism. One study has shown that asymptomatic carriage increased to $48 \%$ after the subjects were given antibiotics. ${ }^{45}$ In the community it has been suggested that pets may also play a role as a source of $C$ difficile infection. ${ }^{46}$ Enteric infection control methods should include isolation of infected patients and wearing of disposable gloves and aprons, strict hand washing, rigorous cleaning procedures, including "deep" cleaning of wards where several cases have occurred, restriction of staff and patient movement, and restriction of antibiotic usage. It is possible to keep groups of affected patients in a single ward, as long as they are "cohort nursed". After initiation of such methods during a serious outbreak in Manchester, there was a substantial and sustained decrease in the number of new cases. ${ }^{47}$ For further information, readers are directed to a recent review of the control and treatment of $C$ difficile infections. ${ }^{48}$

\section{Conclusions}

Although a great deal has been learnt about $C$ difficile in a relatively short period of time, including identification of the intracellular target of the toxins, there remains much still to be understood. Why infants seem to be resistant to the action of the toxins, and whether or not there may be rare exceptions to this and subsequent disease development, needs further study. The availability of diagnostic kits for rapid detection of toxin has greatly enhanced the ability of pathology laboratories to identify cases of $C$ difficile infection. However, little thought has accompanied their widespread use regarding the possible over aggressive response in treatment. By and large, the response to a positive laboratory finding is immediate specific treatment with vancomycin or metronidazole, even though it is well established that cessation of the antibiotic, when possible, is often sufficient. The extent to which "unnecessary" treatment contributes to recurrent bouts of infection is unknown, but it is the opinion of the authors that this is undoubtedly so in some cases. The real problem of treating recurrences and relapses is also still unresolved. Unfortunately, the increasing numbers of hospitalised elderly patients, the highest risk patient group for $C$ difficile infection, means that the incidence of this infection will continue to rise, and may eventually rival MRSA as the most common identifiable nosocomial infection.

1 Borriello SP. Clostridial disease of the gut. Clin Infect Dis 1995;20(Suppl 2):S242-50.

2 Feldman RJ, Kallich M, Weinstein MP. Bacteremia due to Clostridium difficile: Case report and review of extra intestinal C. difficile infections. Clin Infect Dis 1995; 20:1560-2.

3 Cooke EM, Borriello SP, Brazier JS, Cookson BD, Duckworth MB, Duerden BI, et al. Clostridium difficile infection - Prevention and management. A report by a DOH/PHLS joint working group. Lancashire: BAPS Health Publication Unit, 1994.

4 Finney JMT. Gastroenterostomy for cicatrizing ulcer of the pylorus. Bull fohns Hopkins Hosp 1893;4:53-5.

5 Goulston SJM, McGovern VJ. Pseudomembranous colitis. Gut 1965;6:207-12.

6 Anonymous. Pseudomembranous enterocolitis. Lancet 1954;i:228-9.

7 Dawson-Edwards P, Morrisey DM. Acute enterocolitis following partial gastrectomy. Br ₹ Surg 1955;42:643-50.

8 Finegold SM, Harada NE, Miller LG. Lincomycin: Activity against anaerobes and effect on normal human fecal flora. Antimicrob Agents Chemother 1966;6:659-77.

9 Dane TEB, King EG. Fatal pseudomembranous enterocolitis following clindamycin therapy. $\mathrm{Br} f$ Surg 1976; 63:305-8.

10 Bartlett JG, Onderdonk AB, Cisneros RL. Clindamycinassociated colitis due to a toxin producing species of associated colitis due to a toxin producing species
Clostridium in hamsters. $\mathcal{F}$ Infect $D$ is 1977;135:701-5.

11 Rifkin GD, Fekety FR, Silva J, Sack RB. Antibiotic-induced colitis. Implication of a toxin neutralised by Clostridium sordellii antitoxin. Lancet 1977;ii:1103-6.

12 Bartlett JG, Moon N, Chang T-W, Taylor N, Onderdonk AB. Role of Clostridium difficile in antiobiotic-associated pseudomembranous colitis. Gastroenterology 1978; 75:778-82

13 Martinez RD, Wilkins TD. Comparison of Clostridium sordellii $\mathrm{HT}$ and $\mathrm{LT}$ toxins with toxins $\mathrm{A}$ and $\mathrm{B}$ of $\mathrm{C}$. difficile. dellii HT and LT toxins with toxir

14 George RH, Symmonds JM, Dimmock F, Brown JD, Arabi $\mathrm{Y}$, Shinagawa $\mathrm{N}$, et al. Identification of Clostridium difficile as a source of pseudomembranous colitis. $B M \mathcal{F}$ 1978;1:695.

15 Larson HE, Price AB, Honour P, Borriello SP. Clostridium difficile and the aetiology of pseudomembranous colitis. Lancet 1978;i:1063-6.

16 Tenedesco FJ. Pseudomembranous colitis: Pathogenesis and therapy. Med Clin North Am 1982;66:655-64.

17 Whitehead R. Mucosal biopsy of the gastrointestinal tract. Philedelphia: Saunders, 1985.

18 Bartlett JG. Antimicrobial agents implicated in Clostridium difficile toxin-associated diarrhea or colitis. Fohns Hopkins Med F 1981;149:6-9.

19 Amand A, Bashey B, Mir T, Glatt AE. Epidemiology, clinical manifestations and outcome of Clostridium difficileassociated diarrhea. Am ₹ Gastroenterol 1994;8:519-23.

20 Barthram JD, Dunstan FDJ, Hill D, Hosein IK, Pippen CAR. Clostridium difficile: The association between antibiotic therapy and the incidence of infection in the elderly. Pharmaceut F 1995;255:276-8.

21 Borriello SP, Larson HE. Antibiotic and pseudomembranous colitis. $\mathcal{f}$ Antimicrob Chemother 1981;7(Suppl A): 53-62. 
22 Borriello SP, Barclay FE. An in-vitro model of colonisation resistance to Clostridium difficile infection. $7 \mathrm{Med}$ Microbiol 1986;21:299-309.

23 Borriello SP. Clostridium difficile and its toxin in the gastrointestinal tract in health and disease. Res Clin Forum 1979;1:33-5.

24 Libby JM, Danta SF, Wilkins JD. Clostridium difficile toxin A in infants. F Infect Dis 1983;148:606.

25 Borriello SP Pathogenesis of Clostridium difficle infection of the gut. F Med Microbiol 1990;33:207-15.

26 Borriello SP, Davies HA, Kamiya S, Reed PJ, Seddon S Virulence factors of Clostridium difficile. Rev Infect Dis 1990;12(Suppl 2):S185-91.

27 Barroso LA, Wang S-Z, Phelps CJ, Johnson JL, Wilkins TD. Nucleotide sequence of Clostridium difficile toxin $\mathrm{B}$ gene. Nucleic Acids Res 1990;18:4004.

28 Dove CH, Wang S-Z, Price SB, Phelbs CJ, Lyerly DM, Wilkins TD, et al. Molecular characterisation of the Wilkins TD, et al. Molecular characterisation of the 58:480-8.

29 Reigler M, Sedivy R, Pothoulakis C, Hamilton G, Zacheri J Bischof $\mathrm{G}$, et al. Clostridium difficile toxin $\mathrm{B}$ is more potent than toxin $\mathrm{A}$ in damaging human colonic epithelium in vitro. $\mathcal{F}$ Clin Invest 1995;95:2004-11.

30 Lverly DM, Saum KE, MacDonald DK, Wilkins TD. Effects of Clostridium difficile given intragastrically to animals. Infect Immun 1985;47:349-52.

31 Just I, Selzer J, von Eichel-Streiber C, Aktories K. The low molecular mass GTP-binding protein Rho is affected by molecular mass GTP-binding protein Rho is affected by toxin A from

32 Dillon ST, Rubin EJ, Yakubovich M, Pothoulakis C, Lamon JT, Feig LA, et al. Involvement of Ras-related Rho protein in the mechanisms of action of Clostridium difficile toxin $\mathrm{A}$ and toxin B. Infect Immun 1995;63:1421-6.

33 Giry M, Popoff MR, von Eichel-Streiber C, Boquet P. Transient expression of Rho A, -B and -C GTPases in HeLa cells potentiates resisitance to Clostridium difficile toxins $\mathrm{A}$ and $\mathrm{B}$ but not to Clostridium sordellii lethal toxin. Infect Immun 1995;63:4063-71.

34 Just I, Selzer J, Wilm M, von Eichel-Strieber C, Mamm M, Aktories K. Glucosylation of Rho proteins by Clostridium difficile toxin B. Nature 1995;375:500-3.

35 Hammond GA, Johnson JL. The toxigenic element of Clostridium difficile strain VPI 10463. Microb Pathog 1995;19:203-13.

36 Borriello SP, Wren BW, Hyde S, Seddon SV, Sibbons P, Krishna MM, et al. Molecular, immunological and biological chracterisation of a toxin A-negative, toxin B-positive strain of Clostridium difficile. Infect Immun 1992;60:4192-9.

37 Lyerly DM, Barroso LA, Wilkins TD, Depitre C, Corthier G. Chracterisation of a toxin A-negative, toxin B-positive strain of Clostridium difficile. Infect Immun 1992; 60:4633-9.

38 von Eichel-Streiber C, Meyer zum Heringdorf D, Habermann E, Sartingen S. Closing in on the toxic domain through analysis of a variant Clostridium difficile cytotoxin B. Mol Microbiol 1995;17:313-21.

39 Duerden BI, McCartney AC, Borriello SP, Cowden JM, פ Hudson MJ, Painter MJ, et al. Report of the PHLS Clostridium difficile working group. PHLS Microbiol Dig 은 1994;11:22-4.

40 Arrow SA, Croese L, Bowman RA, Riley TV. Evaluation of $\overline{\bar{\omega}}$ three comercial enzyme-immunoassay kits for detecting faecal Clostridium difficile toxins. $\mathcal{f}$ Clin Pathol 1994; 47:954-6.

41 Wilcox MH, Spencer RC. Clostridium difficile infection: $\overline{\bar{c}}$ responses, relapses and re-infections. f Hosp Infoct $\overrightarrow{\mathbb{D}}$ 1992;22:85-92.

42 Surawicz OM, McFarland LV, Elmer GW, Chinn J. O Treatment of recurrent Clostridium difficile colitis with vancomycin and Saccharomyces boulardii. Am F Gastroen- $\overrightarrow{0}$ terol 1989;84:1285-7

43 Schellenberg D, Bonington A, Champion CM, Lancaster R, Webb S, Main J. Treatment of Clostridium difficile diarrhoea with brewer's yeast (letter). Lancet 1994; 343:171-2.

44 Fekety R, Kim K-H, Brown D, Batts DH, Cudmore M, Silva J. Epidemiology of antibiotic-associated colitis: Isolation of Clostridium difficile from the hospital environment. Am F Med 1981;70:906-8.

45 George WL. Antimicrobial agent-associated diarrhea in N adult humans. In: Rolfe RD, Finegold SM, eds. Clostridium difficile - its role in intestinal disease. London: Aca-음 demic Press, 1988:31-44.

46 Borriello SP, Honour P, Turner T, Barclay F. Household pets as a potenetial resevoir for Clostridium difficile infec- $\subseteq$ tion. F Clin Pathol 1983;36:84-7.

47 Cartmill TDI, Panigrahi, MA, Worsley MA, McCann DC, Nice $\mathrm{CN}$, Kieth E. Management and control of a large outbreak of diarrhoea due to Clostridium difficile. $\mathcal{F}$ Hosp Infect 1994;27:1-5.

48 Tabaqchali S, Jumaa P. Diagnosis and management of Clostridium difficile infection. BMF 1995;310:1375 -80. 